\title{
A atitude investigativa no trabalho do assistente social
}

\section{The investigative attitude in the social worker's job}

\section{Cristina Kologeski Fraga*}

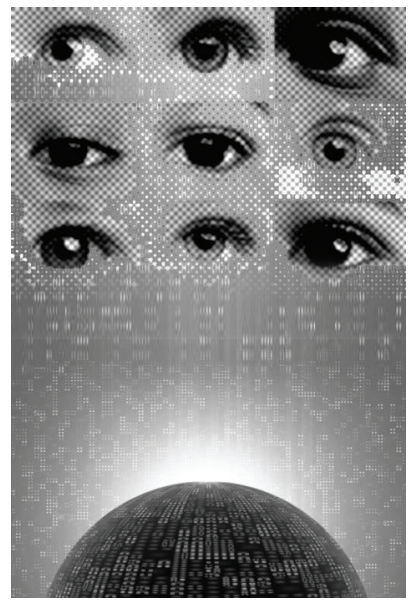

Resumo: O artigo trata da atitude investigativa no trabalho do assistente social - AS. Para tanto, discorre sobre os componentes do trabalho do AS, dando visibilidade às suas competências e especificidades. Na sequência, discute a atitude investigativa no exercício profissional. Propõe que, além da articulação entre investigação/ação no cotidiano de trabalho, torna-se fundamental uma atitude interdisciplinar. Finalmente, sugere o trabalho do assistente social envolto numa equação tensionada pelo pragmatismo - atitude investigativa, mediada pela intervenção, que só adquire alcance social quando pautada pela interdisciplinaridade.

Palavras-chave: Atitude investigativa. Pesquisa. Intervenção. Interdisciplinaridade.

\begin{abstract}
The article addresses the investigative attitude in the social worker's job - SW. To do so, it deals with the parts of the SW's job, by providing visibility to their competencies and specificities. Next, it discusses the investigative attitude in the professional activity. After, it shows that, in addition to the articulation between investigation/action in the daily work, it becomes fundamental an interdisciplinary attitude. Finally, it suggests the SW's job to be involved in an equation of pragmatism investigative attitude, mediated by intervention, that only gets to social reach when it's guided by interdisciplinarity.
\end{abstract}

Keywords: Investigative attitude. Research. Intervention. Interdisciplinarity.

* Assistente Social, mestre e doutora em Serviço Social (PUC-RS). Atualmente é professora adjunta do Curso de Serviço Social da Universidade Federal do Pampa — Unipampa/Campus São Borja/RS — Brasil. E-mail: ckfraga@hotmail.com. 


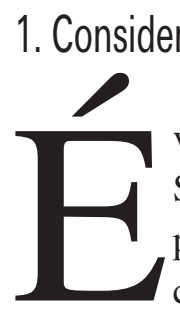

voz corrente entre os profissionais da área e de outros setores que o Serviço Social — SS é uma profissão essencialmente interventiva. A partir dessa noção convencionou-se caracterizar o Serviço Social como uma profissão de intervenção na realidade social, e o assistente social - AS —, profissional da área, seria, então, aquele profissional imerso no pragmatismo, ${ }^{1}$ habilitado para intervir nas diferentes manifestações da questão social. O objetivo deste artigo é problematizar e desconstruir essa visão pragmática acerca do trabalho do assistente social com vistas a resgatar sua dimensão investigativa. Parte-se da premissa de que o exercício profissional do assistente social exige uma atitude investigativa constante para que não se torne meramente pragmática, sem intencionalidade e clareza de finalidade.

Tal assertiva remete, necessariamente, às inquietações interrogativas advindas de um desassossego da experiência da autora como assistente social, formada há uma década, e de sua posterior inserção na docência em Serviço Social ${ }^{2}$ e como pesquisadora da área. ${ }^{3}$ A relação entre a atitude investigativa e a pesquisa no trabalho do assistente social aporta um confronto de interrogações no âmbito profissional e pessoal da autora que, em virtude de sua atuação nos últimos três anos na formação de graduação em Serviço Social, em diferentes instâncias pedagógicas, nos espaços formais ${ }^{4}$ e informais, ${ }^{5}$ deram origem aos insumos básicos à elaboração deste texto.

1. Neste texto conceitua-se pragmatismo a partir de Faleiros (1986, p. 5): “O pragmatismo consiste numa atitude voltada para a solução de problemas imediatos, sem pensar e refletir as consequências teóricas e históricas desta ação imediata”.

2. Docente nos cursos de graduação em Serviço Social, supervisora acadêmica, coordenadora de estágio em Serviço Social, orientadora de Trabalho de Conclusão de Curso, coordenadora de curso em Serviço Social. (N.E.)

3. Muito embora se deva explicitar que o objeto de estudos da autora esteve voltado para "A saúde do trabalhador, com foco no acidente de trabalho", é um tema transversal que perpassa a intervenção profissional do assistente social e foi preciso apreendê-lo como uma forma de violência visível e invisível, contextualizada numa dinâmica construída no seio das relações sociais, econômicas e políticas, culturalmente aceitas ou não. (N.E.)

4. Para fins deste texto, está se referindo a espaços formais como aqueles constituídos no âmbito de atuação profissional, no espaço universitário, acadêmico, nos espaços de diálogo com as assistentes sociais de campo, nas reuniões com as colegas docentes AS, nos encontros, seminários e congressos da categoria. (N.E.)

5. Os espaços informais, neste texto, estão sendo referenciados como aqueles constituídos fora do âmbito de atuação profissional, nos diálogos de "bar", de intervalos de aula, de confraternização com 
Entre as questões que motivaram e mobilizaram a abordagem deste assunto, procurou-se dissertar sobre aquelas que pareceram importar ao debate da categoria em pleno século XXI, como, por exemplo, qual é a relação entre a atitude investigativa e o trabalho do assistente social na contemporaneidade? Por outro lado, como o AS pode atuar se não investiga, se é um profissional que trabalha com a viabilização do acesso aos direitos dos usuários? Como refletir e construir conhecimento sem a pesquisa do cotidiano de trabalho profissional? Como atuar efetivamente sem suporte investigativo?

O delineamento desses questionamentos permitiu, também, formular a premissa básica de que a atitude investigativa é o fomento básico do exercício profissional do assistente social que se refere ao movimento de desocultamento do real, e também que esse profissional, assim como o de outras áreas, só investiga aquilo que conhece e o incomoda: "Ou seja, nada pode ser intelectualmente um problema, se não tiver sido, em primeiro lugar, um problema da vida prática" (Minayo, 1999, p. 17).

Em termos de estrutura, o texto está organizado em itens que permitem elucidar o tema em foco. Assim, primeiramente será abordado aspectos do trabalho do assistente social. A seguir discorrer-se-á sobre as especificidades dos processos investigativos no trabalho profissional do assistente social. $\mathrm{Na}$ sequência, será abordada a importância da interlocução do assistente social com diferentes áreas profissionais, indicando possibilidades a serem consideradas na busca interdisciplinar para uma atuação com maior alcance social nas diferentes manifestações da questão social. Por fim, serão tecidas algumas considerações em torno do ato/postura de investigação/ação do assistente social.

\section{Componentes do trabalho profissional do assistente social}

Historicamente o Serviço Social foi considerado vocação, habilidade, ocupação, ofício ou até mesmo arte. Atualmente é reconhecido como profissão, uma especialização do trabalho coletivo, inscrita na divisão social e técnica do os acadêmicos do curso de Serviço Social, com as colegas AS, com as colegas docentes assistentes
sociais. (N.E.) 
trabalho, de nível superior, regulamentada no Brasil pela Lei n. 8.662/9, de 7 de junho de 1993. De acordo com Netto (1999, p. 102),

enquanto profissão, não dispõe de uma teoria própria, nem é uma ciência; isto não impede, entretanto, que seus profissionais realizem pesquisas, investigações etc. e produzam conhecimentos de natureza teórica, inseridos no âmbito das ciências sociais e humanas.

Embora não tendo atingido o patamar de "ciência", o Serviço Social conseguiu se constituir como uma área de produção de conhecimentos, inserida na grande área de Ciências Sociais Aplicadas (assim é identificada nas agências de fomento como CNPq, Capes e Fapergs), isto é, constrói conhecimento ${ }^{6}$ científico. O Serviço Social é uma profissão reconhecida na sociedade na medida em que é socialmente necessária e exercida por um grupo social específico, uma categoria profissional que compartilha um sentimento de pertencimento e possui uma identidade profissional. ${ }^{7}$

As mudanças na concepção que se tem da profissão de assistente social são consequências de processos históricos, e dependem do significado social que se atribui à profissão, que é fruto de movimentos da categoria e também da sua relação com a dinâmica e o desenvolvimento do conjunto da sociedade. Atualmente, além de ser uma profissão, o Serviço Social é considerado trabalho.

A abordagem do Serviço Social como trabalho foi protagonizada por Iamamoto em 1982 (Iamamoto e Carvalho, 1995), corroborada, posteriormente, pela Abepss, a partir do processo de revisão curricular de ensino de graduação em Serviço Social no Brasil, que redundou na proposta de Diretrizes Gerais para o Curso de Serviço Social, respondendo a uma exigência da Lei de Diretrizes e Bases da Educação Nacional (Iamamoto, 1998).

6. O conhecimento concebido conforme proposto por Setúbal (2002, p. 31): “[...] como produto de um processo metodologicamente construído, ou seja, pelo conhecimento produzido a partir da pesquisa em Serviço Social [...] uma elaboração intelectual resultante do processo que ultrapassa o plano meramente sensível, pela mediação do raciocínio lógico, dialético e da consciência sobre a realidade do objeto observado presentes na produção de conhecimento, nas atitudes e no modo de agir do Serviço Social".

7. Sobre essa discussão, no âmbito do Serviço Social, consultar Martinelli (1997). 
Alguns elementos realçados por Iamamoto também são sinalizados neste espaço para subsidiar a abordagem do processo de trabalho do assistente social, pois esse documento aponta a centralidade da categoria trabalho como fundamental ao debate contemporâneo do Serviço Social, porque o trabalho é "uma atividade fundamental do homem, pois mediatiza a satisfação de suas necessidades diante da natureza e de outros homens [...]. O trabalho é, pois, o selo distintivo da atividade humana" (Iamamoto, 1998, p. 60).

Assim, de acordo com Prates (2003), apreender o Serviço Social como trabalho significa considerar os elementos que integram o processo de trabalho ${ }^{8}$ dos assistentes sociais como partes indissociáveis, reconhecendo que o assistente social é um trabalhador que desenvolve um processo de trabalho: "o trabalho do assistente social na sociedade capitalista produz um valor de uso (o serviço oferecido ao usuário, aos grupos, à comunidade, às organizações e às instituições) e um valor de troca (preço pago por este serviço no mercado de trabalho)" (Prates, 2003, p. 108).

Sendo assim, desvendar o objeto de trabalho pelo qual o assistente social atua é essencial para o desenvolvimento de um processo de trabalho consistente. Portanto, conhecer como a questão social se manifesta no cotidiano dos sujeitos sociais e suas formas de organização e resistência é imprescindível para que se tenham subsídios para construir coletivamente alternativas para o seu enfrentamento.

A questão social, considerada pela categoria profissional como a base de sua fundação na especialização do trabalho do assistente social, precisa ser apreendida na contradição fundamental da sociedade capitalista:

Questão social que, sendo desigualdade é também rebeldia, por envolver sujeitos que vivenciam as desigualdades e a ela resistem e se opõem. É nesta tensão entre produção de desigualdade e produção da rebeldia e da resistência, que trabalham os assistentes sociais, situados neste terreno movido por interesses sociais distintos, aos quais não é possível abstrair ou fugir deles porque tecem a vida em sociedade. (Iamamoto, 1998, p. 28)

8. A respeito desta abordagem do processo de trabalho do assistente social é interessante consultar Iamamoto (1998), Almeida (1996), Barbosa, Cardoso e Almeida (1998) e Prates (2003). 
O cerne da questão social está enraizado no conflito entre capital versus trabalho, suscitado entre a compra (detentores dos meios de produção) e venda da força de trabalho (trabalhadores), que geram manifestações e expressões. Estas manifestações e expressões, por sua vez, são subdivididas entre a geração de desigualdades: desemprego, exploração, analfabetismo, fome, pobreza, entre outras formas de exclusão e segregação social que constituem as demandas de trabalho dos assistentes sociais; também se expressa pelas diferentes formas de rebeldia e resistência: todas as maneiras encontradas pelos sujeitos para se opor e resistir às desigualdades, como, por exemplo, conselhos de direitos, sindicatos, políticas, associações, programas e projetos sociais.

Desta forma, a finalidade do trabalho do assistente social está voltada para a intervenção nas diferentes manifestações da questão social com vistas a contribuir com a redução das desigualdades e injustiças sociais, como também fortalecer os processos de resistências dos sujeitos (materializados em organizações sociais, movimentos sociais, conselhos de direitos...), na perspectiva da democratização, autonomia dos sujeitos e do seu acesso a direitos.

Para tanto, o assistente social deverá imprimir em sua intervenção profissional uma direção, sendo necessário, para isto, conhecer e problematizar o objeto de sua ação profissional, construindo sua visibilidade a partir de informações e análises consistentes - atitude investigativa. Concomitantemente, o trabalho do AS deverá ser norteado por um plano de intervenção profissional objetivando construir estratégias coletivas para o enfrentamento das diferentes manifestações de desigualdades e injustiças sociais, numa perspectiva histórica que apreenda o movimento contraditório do real. Isto pressupõe:

a) pesquisar dados de realidade quantitativos, pois de acordo com Martinelli (1994), as pesquisas quantitativas são imprescindíveis para trazer retratos da realidade, dimensionar os problemas que se investiga;

b) investigar sobre as informações qualitativas da realidade. Conforme Martinelli (1994), as metodologias qualitativas aproximam pesquisador/ sujeitos pesquisados, permitindo ao primeiro conhecer as percepções dos segundos, os significados que atribuem a suas experiências, seus modos de vida, ou seja, oferece subsídios para trabalhar com o real em movimento, em toda a sua plenitude; 
c) desvendar e problematizar a realidade social, apreendendo os modos e as condições de vida dos sujeitos com seus condicionantes históricos, sociais, econômicos e culturais, e também seus anseios, desejos, necessidades, demandas;

d) intervir na realidade social com base na apreensão do movimento contraditório do real, a partir do seu desvendamento e problematização, e também de pesquisas sobre dados da realidade dos sujeitos.

O Serviço Social é uma profissão investigativa e interventiva. Portanto, as análises de seus estudos e pesquisas precisam ser realizadas a partir de situações concretas e possuir utilidade social, não interessando o conhecimento realizado apenas com finalidade descritiva e contemplativa. Para que os estudos e pesquisas tenham utilidade social é fundamental, além da clareza do projeto ético-político ${ }^{9}$ construído coletivamente pela categoria, o domínio teórico-metodológico ${ }^{10}$ e técnico-operativo, ${ }^{11}$ alicerçados pelo conjunto de conhecimentos, habilidades, atribuições, competências e compromissos necessários à realização dos processos de trabalho, em qualquer espaço ou âmbito de atuação onde o assistente social o realize.

O AS exerce sua atividade profissional em diversos espaços, âmbitos, áreas, segmentos populacionais (criança e adolescente, idoso, pessoas portado-

9. O projeto ético-político tem como seus pilares básicos o Código de Ética Profissional dos Assistentes Sociais/Resolução CFESS n. 273/93 de 13 de março de 1993 (Conselho Federal de Serviço Social, 1993a), a Lei de Regulamentação da profissão/Lei n. 8.662/9, de 7 de junho de 1993 e as diretrizes curriculares do curso de Serviço Social. Este último pilar possui nortes básicos expressos nos documentos: Abepss, 1996; Diretrizes..., 1997. Sobre o projeto ético-político, é interessante ver também: Netto, 1999; Sant'Ana, 2000.

10. Segundo Nogueira (2005, p. 185), a dimensão teórico-metodológica está voltada para o modo, a maneira de ler e interpretar os fenômenos sobre os quais a profissão se debruça. Na visão de Silva (1999), o consistente conhecimento teórico-metodológico propicia aos profissionais uma compreensão clara da realidade social e a identificação das demandas e possibilidades de ação profissional que esta realidade apresenta.

11. A capacitação técnico-operativa ou técnico-operacional é a dimensão que possibilita, conforme Silva (1999, p. 113), "a definição de estratégias e táticas na perspectiva da consolidação teórico-prática de um projeto profissional compromissado com os interesses e necessidades dos usuários, com a defesa dos direitos sociais, com a ampliação da esfera pública e com a construção de uma nova cidadania social, capaz de realizar e impulsionar novos direitos, mediante o fortalecimento da consciência de classe e da organização política, sindical e comunitária". 
ras de necessidades especiais, família) ${ }^{12}$ e em diferentes setores (seguridade social: saúde, previdência social, assistência social; educação, trabalho, habitação e na questão agrária). Dessa multiplicidade de possibilidades de atuação advém também uma variedade de processos de trabalho, o que exige desse profissional um arsenal de conhecimentos variados.

Esse arsenal de conhecimentos ético-político, teórico-metodológico e técnico-operativo do qual o assistente social precisa apropriar-se no seu âmbito de atuação profissional varia, desde os considerados específicos, decorrente da área de Serviço Social propriamente dita, como também apropriações sobre legislações (principalmente a relativa à legislação social voltada para a criança e o adolescente — ECA; idoso — Estatuto do Idoso; SUS — Sistema Único de Saúde; Loas — Lei Orgânica de Assistência Social; Sistema Único de Assistência Social - Suas; Suas/RH; Política Nacional de Pessoas Portadoras de Deficiência - PPD; Lei de Diretrizes e Bases — LDB); políticas sociais, conhecimento e habilidade de trabalhar em equipes, interfaces com poder público local, articulação de redes e com instâncias locais diversas, o que requer, além da formação generalista, apropriações aprofundadas dependendo da inserção sócio-ocupacional.

Na questão dos espaços sócio-ocupacionais, o assistente social pode atuar em entidades públicas, tais como: prefeituras, Judiciário, Ministério Público, Instituto Nacional de Seguro Social - INSS, escolas, albergues, abrigos, sistema carcerário (presídios e penitenciárias), Fase, hospitais, e também em entidades privadas: empresas de serviços, de comércio, de indústria. No denominado terceiro setor, poderá atuar em entidades socioassistenciais, associações de moradores, Organizações Não Governamentais - ONGs. Além disso, poderá atuar também nas áreas de ensino e pesquisa, de maneira autônoma, com assessoria e consultoria em projetos de gestão e planejamento social.

Diante desse amplo leque de possibilidades de atuação profissional, a Lei de Regulamentação da Profissão de Assistente Social estabelece as balizas da

12. A respeito da intervenção profissional do assistente social com famílias, é interessante consultar os estudos de Regina Célia Tamaso Mioto, especialmente o artigo intitulado "Trabalho com famílias: um desafio para os assistentes sociais" (2004). 
ação para esses profissionais, de modo a clarificar as atribuições que lhes são privativas, como também competências ${ }^{13}$ adquiridas ao longo de sua constituição, deslindando o papel do assistente social para a própria categoria profissional e para seus empregadores.

As competências previstas ao assistente social estão explicitadas no art. $4^{\circ}$ (nos incisos de I a XI) da Lei de Regulamentação da Profissão — Lei n. 8.662/9, de 7 de junho de 1993, que, de maneira sucinta, prevê ao assistente social as atividades descritas no Quadro 1, disposto na sequência (CFSS, 1993b).

\section{Quadro 1}

Competências previstas ao assistente social no art. $4^{\circ}$, da

Lei de Regulamentação da Profissão — Lei n. 8.662/93

\begin{tabular}{|l|}
\hline Rol de atividades previstas como competências do assistente social \\
\hline — planejar, organizar, administrar: benefícios e serviços sociais; \\
\hline — planejar, executar, avaliar pesquisas (para análise da realidade social e para subsidiar a ação \\
profissional); \\
\hline — assessoria/consultoria: órgãos públicos, empresas privadas, outras entidades; \\
\hline — assessoria, apoio, defesa, exercício de direitos (sociais, civis e políticos): movimentos sociais; \\
\hline — implementar, elaborar, executar, avaliar: políticas sociais (junto à administração pública, empresas, \\
entidades, organismos populares); \\
\hline — elaborar, coordenar, executar, avaliar: planos, programas e projetos juntamente com a sociedade \\
civil; \\
\hline — providências: encaminhar, orientar — indivíduos, grupos, populações; \\
\hline — orientar: indivíduos e grupos a identificar recursos, fazer uso, atender e defender direitos; \\
\hline — realizar estudos socioeconômicos com usuários: benefícios e serviços sociais; \\
\hline — planejar, organizar, administrar: serviços sociais/unidades de Serviço Social. \\
\hline
\end{tabular}

Fonte: Síntese elaborada pela autora, com base no art. $4^{\circ}$ da Lei de Regulamentação da Profissão — Lei n. 8.662, de 7 de junho de 1993 (CFSS, 1993b).

13. Competências são genéricas e expressam capacidade para apreciar ou dar resolutividade a determinado assunto, não sendo exclusiva de uma única especialidade profissional, mas a ela pertencem em função da capacitação dos profissionais (Iamamoto, 2002). (N.E.) 
Vale ressaltar que, de acordo com Iamamoto (2002), a respeito dos referidos artigos da Lei de Regulamentação da profissão, os incisos II, III, VIII e XI, do art. $4^{\circ}$, embora colocados como competências, são, na realidade, atribuições privativas do assistente social, pois o que delimita o caráter da atividade como exclusiva do assistente social é a sua qualificação enquanto matéria, área e unidade $^{14}$ de Serviço Social. Além disso: "apresentam competências que também estão previstas no art. $5^{\circ}$. da referida lei concernente às atribuições privativas" (Iamamoto, 2000, p. 17).

No que se refere as atribuições privativas ${ }^{15}$ do assistente social, estão explicitadas no art. $5^{\circ}$, (nos incisos de I a XIII) da Lei de Regulamentação da Profissão — Lei n. 8.662, de 7 de junho de 1993 que, sumariamente, prevê ao assistente social as atividades explicitadas no Quadro 2, a seguir:

\section{Quadro 2}

Atribuições privativas asseguradas ao assistente social no art. $5^{\circ}$ da

Lei de Regulamentação da Profissão — Lei n. 8.662, de 7 de junho de 1993

Rol de atividades asseguradas como atribuições privativas do assistente social

— realizar vistorias, perícias técnicas, laudos periciais, informações, pareceres (em matéria de Serviço Social);

— magistério de Serviço Social (graduação e pós-graduação): assumir disciplinas e funções que exijam conhecimentos específicos;

— direção/coordenação de unidades de ensino e cursos de Serviço Social (graduação e pós-graduação);

— supervisão direta de estagiários de Serviço Social: treinamento, avaliação;

— assessoria e consultoria (em matéria de Serviço Social) — órgãos públicos, empresas privadas, outras entidades;

— associações, núcleos, centros de ensino e pesquisa: dirigir, coordenar;

continua..

14. Sinteticamente Iamamoto (2002) distingue matéria, área e unidade da seguinte maneira: a matéria é o objeto ou assunto sobre o que particularmente se exerce a força de um agente; a área é o campo delimitado ou âmbito de atuação do assistente social, enquanto unidade pode ser definida como sendo o conjunto de profissionais de uma unidade de trabalho. (N.E.)

15. Atribuições privativas: são prerrogativas exclusivas, privilégio de uma área, direito e poder de realizar algo, é exclusiva e designada como atribuição (Iamamoto, 2002). (N.E.) 
continuação

— provas, bancas examinadoras, comissões, concursos/seleção: elaborar, presidir, compor, aferir
conhecimentos;
— estudos/pesquisas, planos, programas, projetos (na área de Serviço Social): elaborar, coordenar,
executar, avaliar, supervisionar;
— fiscalizar o exercício profissional — por meio dos conselhos (Cress e CFESS);
— órgãos e entidades representativos da categoria: ocupar cargos, dirigir, fiscalizar (gestão financeira);
— dirigir serviços técnicos de Serviço Social: entidades públicas ou privadas;
— coordenar seminários, encontros, congressos e eventos de Serviço Social;
— planejar, organizar, administrar: programas e projetos em Unidade de Serviço Social.

Fonte: Síntese elaborada pela autora, com base no art. $5^{\circ}$ da Lei de Regulamentação da Profissão — Lei n. 8.662, de 7 de junho de 1993 (CFSS, 1993b).

A Lei de Regulamentação da Profissão estabelece os parâmetros legais que asseguram as competências ao assistente social e ampara suas prerrogativas exclusivas a cada profissional que precisa, então, ter ciência de seu teor para lançar mão desse aparato legal, nos diferentes âmbitos de atuação profissional.

Isso posto, vale ressaltar que a referida lei é um instrumento que só terá sua efetividade e alcance no coletivo da categoria, na medida em que cada assistente social tiver clareza de finalidade no seu exercício profissional cotidiano, visto que quem não sabe onde quer ir, perde-se no caminho e não chega a lugar nenhum.

\section{A atitude investigativa no cotidiano de trabalho do assistente social}

A Abepss (1996), na proposta das Diretrizes Gerais para o Curso de Serviço Social, postula como princípios da formação profissional (entre outros), o estabelecimento das dimensões investigativa e interventiva como princípios formativos que devem perpassar a formação profissional e da relação teoria e realidade; recomenda a questão do caráter interdisciplinar nas várias dimensões do projeto de formação profissional do assistente social. Afirma ainda que a grade curricular do curso deve possibilitar uma indissociabilidade nas dimen- 
sões de ensino, pesquisa e extensão. Ao ser mencionado o conjunto de conhecimentos indissociáveis, que se traduzem em núcleos de fundamentação constitutivos da formação profissional, vale trazer a lume que o denominado Núcleo de Fundamentos do Trabalho Profissional sinaliza: "A postura investigativa é um suposto para a sistematização teórica e prática do exercício profissional, assim como para a definição de estratégias e o instrumental técnico que potencializam as formas de enfrentamento da desigualdade social" (Abepss, 1996, p. 67). A Pesquisa ${ }^{16}$ em Serviço Social, é apresentada como uma das matérias básicas do curso.

Antes de se problematizar acerca da atitude investigativa no exercício profissional do assistente social, é importante ter presente que o atual Código de Ética do Assistente Social prevê como um dos seus onze princípios fundamentais a questão do compromisso com a qualidade dos serviços prestados à população e com o aprimoramento intelectual ${ }^{17}$, na perspectiva de competência profissional. Tal princípio remete ao que Battini (1994) propõe a denominada "atitude investigativa".

Para se entender o que seria atitude investigativa, pode-se recorrer às metáforas do olhar do viajante turista e do viajante expedicionário. O que é um viajante turista? No Dicionário de Língua Portuguesa Novo Aurélio Século XXI, turista é aquela pessoa que faz turismo, enquanto turismo seria uma viagem ou excursão, realizada por prazer, a locais que despertam interesse. O olhar do turista divaga. O seu objetivo é o de passeio. Já na expedição o objetivo do viajante está ligado a explorar, pesquisar, estudar uma região, geralmente em caráter científico.

A questão que se coloca ao profissional, então, seria quando seu exercício profissional remete ao caráter turista ou expedicionário no cotidiano de trabalho? Depende da postura e do olhar. Pode-se referir a um profissional turista quando sua postura, como sujeito, não busca mergulhar no desconhecido; se o seu olhar

16. Em termos gerais concebe-se pesquisa como "a atividade básica da Ciência na sua indagação e construção da realidade" (Minayo, 1999, p. 17).

17. O que enseja a necessidade de uma formação profissional continuada no âmbito da categoria de assistentes sociais. 
é ingênuo e acomodado. Nesse caso, seu olhar apenas divaga e vagueia pela paisagem do seu ambiente de trabalho. Contudo, um profissional que se quer de expedição possui uma postura investigativa, o seu olhar é crítico, exigente, seletivo, tem a pretensão de colher informações, saber mais. Nesse segundo caso, o olhar do profissional será curioso, inquieto e sensível.

Nessa linha, pode-se também referir o personagem John Nasch do filme intitulado Uma mente brilhante (A beautiful mind - EUA, 2001). É um viajante de excursão ou de expedição? Diferente dos outros colegas, ele busca uma ideia original para compor sua tese. Seu olhar não é acomodado e limitado ao que já foi produzido, mas não ignora o que já foi produzido. Pelo contrário, busca conhecer para fugir do óbvio. Na sua busca expedicionária, destaca-se sua postura investigativa, de humildade, persistência, crise intelectual e de constante busca. Nasch não tem um tema para sua tese quando chega à universidade; ele quer elaborar uma excelente tese. Para chegar ao seu objetivo, sua busca é incansável: lê muito, desconstrói conceitos, sofre, observa, estranha, contesta.

O que seria, então, a propalada atitude investigativa? Remete a uma postura aberta do sujeito para investigar, a permanente curiosidade, expectativa para aprender e entender o inesperado, o acaso, o que extrapola suas referências e o leva a ir além. A atitude investigativa consiste numa postura inquieta e curiosa, por isso é fundamental na bagagem cotidiana do profissional. A ausência dessa postura pode levar à cristalização das informações, à estagnação do aprendizado profissional, o que, consequentemente, comprometerá o compromisso do assistente social com a qualidade dos serviços prestados à população usuária.

Nessa perspectiva, Battini refere que a atitude investigativa é a permanente busca do novo pela reconstrução de categorias teórico-metodológicas de leitura e intervenção na realidade social, pois:

Pensar os fatos, os acontecimentos, as relações exige questionar, investigar a realidade, criticá-la, tornando-a evidente pela contínua recolocação de questões, fazendo-a emergir de forma cada vez mais rica e viva, recriando-a num contínuo percurso entre a aparência e a essência, entre a parte e o todo, entre o universal e o particular, numa visão dialética. (Battini, 1994, p. 144) 
De acordo com a mesma autora, a atitude investigativa torna possível a superação da visão pragmática na ação profissional, centrada na imediaticidade dos fatos e que privilegia sequências empíricas. Além disso, no exercício profissional do AS, a atitude investigativa desmistifica o fato de que só fazem ciência ou só agem cientificamente aqueles que têm o privilégio de construir o saber, ou seja, os assistentes sociais que estão inseridos nas academias como docentes e pesquisadores, uma vez que tal atitude propicia desvendar, pelas mediações, a realidade aparente.

As ações profissionais dos assistentes sociais, por serem tecidas no cotidiano, não podem ser repetitivas, rotineiras e esvaziadas de sentido, ao contrário, é justamente daí que advém a sua preciosidade, conforme esclarece Martinelli (1994, p. 13): "uma riqueza de vida que poucas profissões têm, temos uma atividade que se constrói na trama do cotidiano, que se constrói nas tramas do real”.

$\mathrm{O}$ assistente social tem uma ação profissional que se tece no dia a dia dos usuários, na particularidade de suas vidas, conforme a mesma autora explicita, transita entre demandas, carências e necessidades que se constituem de ações múltiplas. Sendo assim, esse profissional é desafiado a superar-se constantemente, reconhecendo a realidade sócio-histórica em que vive e trabalha, tornando-se protagonista da construção do projeto ético-político da categoria, que deve assegurar a ampliação da liberdade, ser atuante na consolidação da democracia, garantindo a todos os sujeitos maior equidade e justiça social, enfrentando as contradições e desigualdades socialmente produzidas.

$\mathrm{O}$ assistente social possui uma profissão com características muito singulares, pois diferentemente das demais profissões que atuam sob uma área específica, tal como o professor, o médico, o enfermeiro, o nutricionista, o advogado e outros, ele tem uma profissão que, como um leque, podem ser ventiladas muitas possibilidades de atuação, conforme acentua Carvalho (2005, p. 52):

Ela não atua sobre uma única necessidade humana (tal qual o dentista, o médico, o pedagogo...) nem tampouco se destina a todos os homens de uma sociedade, sem distinção de renda ou classe. Sua especificidade está no fato de atuar sobre todas as necessidades humanas de uma dada classe social, ou seja, aquela formada pelos grupos subalternos, pauperizados ou excluídos de bens, serviços e riquezas dessa mesma sociedade. 
Muito embora concorde-se com a autora citada sobre a multiplicidade de territórios e demandas empreendidas ao Serviço Social, discorda-se de sua afirmação quanto à especificidade de o profissional dessa área atuar unicamente numa classe social específica, a dos desprivilegiados economicamente. Isto porque se considera as expressões da questão social como objeto de trabalho do assistente social, tanto em suas formas de manifestação das desigualdades sociais, como nas formas de resistências empreendidas pelos sujeitos. Percebe-se que são contradições que se materializam de modo diverso em diferentes áreas, para diferentes segmentos sociais, em diferentes âmbitos da vida social, ainda que de maneira prioritária (mas não exclusiva): os segmentos sociais subalternos, pauperizados e excluídos de bens, serviços e riquezas da sociedade capitalista.

Por outro lado, porém, a dinâmica das relações que forjam a intervenção do AS não se inscreve na superfície, no aparente; é preciso resgatar o seu movimento penetrando na sua essência, e isto implica e constitui uma postura investigativa permanente. Para se apreender o trabalho do AS deve-se situá-lo no contexto das relações sociais concretas de cada sociedade, pois a ação do AS é um produto humano construído historicamente. Conforme

O Serviço Social, como as demais profissões, na medida em que se refazem e se constroem as relações na sociedade, vai se reconstruindo e refazendo, muito embora nesse processo não supere os limites das relações postas pelo capitalismo, uma vez que a própria sociedade não os supera. Nesse processo de re-construção, as ações individuais podem assumir, ao mesmo tempo, as dimensões de síntese resultante do processo colectivo de elaboração de conhecimentos e práticas desenvolvidos pela categoria - e de criação de novas propostas e de novos conhecimentos. (Baptista, 2001, p. 15-16)

Kosik (1995), em Dialética do concreto, usa os termos "claro-escuro", "meia-verdade" ao se referir à maneira como a realidade se apresenta, explicando que o mundo real é oculto pela pseudoconcreticidade, apesar de nela se manifestar. Nesse sentido, há uma contradição essencial na realidade que é preciso desvendar, pois:

O mundo da pseudoconcreticidade é um claro-escuro de verdade e engano. O seu elemento próprio é o duplo sentido. $\mathrm{O}$ fenômeno indica a sua essência e, ao mesmo 
tempo, a esconde. A essência se manifesta ao fenômeno, mas só de modo inadequado, parcial, ou apenas sob certos ângulos e aspectos. (Kosik, 1995, p. 15)

Sabe-se que a realidade não se apresenta no aparente de forma total, apenas parcial, pois se assim o fosse, explica Kosik (1995) valendo-se de Marx, seria inútil o papel da ciência e da filosofia. Ao contrário, como a essência diferentemente dos fenômenos - não se manifesta diretamente, e desde que o fundamento oculto das coisas deve ser descoberto mediante uma atividade peculiar, têm de existir a ciência e a filosofia.

A partir das contribuições de Kosik (1995), ter clareza da dubiedade da qual se reveste a realidade social é essencial para o assistente social, para que, imbuído de uma visão de homem e de mundo, de apreensão crítica do objeto de atuação profissional, consiga captar suas contradições. Nessa perspectiva, também são fundamentais as categorias totalidade ${ }^{18}$ e historicidade ${ }^{19}$ inseridas no movimento do real, de maneira que seja possível conceber a ação profissional do AS como uma atividade de desvendamento e transformação da realidade, portanto de investigação e intervenção social: "é na vida real que começa, portanto a ciência real, positiva, a análise da atividade prática, do processo, do desenvolvimento prático dos homens. Cessam as frases ocas sobre a consciência, para que um saber real as substitua" (Marx e Engels, 2002, p. 20).

De forma coerente com a perspectiva marxista de apreensão da realidade, o AS é um trabalhador que parafraseando Marx, atua com o sujeito de "carne e osso", com sua história de vida real. A partir do processo de vida real é possível decifrar as questões que se colocam na singularidade do sujeito, conhecer a realidade social em que está inserido, apreendendo os seus modos e condições

18. A totalidade, na visão de Kosik (1995, p. 49), não significa apreensão de todos os fatos. Significa a percepção da realidade como um todo estruturado, dialético, no qual ou do qual um fato qualquer pode vir a ser racionalmente compreendido. Nesse sentido: "Princípio metodológico da investigação dialética da realidade social é o ponto de vista da totalidade concreta, que antes de tudo significa que cada fenômeno pode ser compreendido como momento do todo".

19. Historicidade significa reconhecer o processo, o movimento e a transformação dos sujeitos, da realidade e dos fenômenos sociais. Significa apreender os fatos como em permanente desenvolvimento e, portanto, apreendê-los em cortes históricos. Para além da cronologia dos fatos que marcam a história, busca-se resgatar fatos significativos. 
de vida com seus condicionantes históricos, sociais, econômicos e culturais, porém também os seus anseios, desejos, necessidades e demandas.

Para se apreender o trabalho do assistente social deve-se situá-lo no contexto das relações sociais concretas de cada sociedade, pois sua ação é um produto humano, uma objetivação construída historicamente, o que requer uma postura investigativa sobre o real, pois esta "é necessária para descortinar as armadilhas da vida cotidiana, passo crucial e insubstituível para uma intervenção profissional crítica, propositiva e, portanto, não repetitiva" (Silva, 2007, p. 11).

Nesse sentido, é preciso considerar as mudanças tecidas na sociedade, pois as transformações que emergem na cena contemporânea e em curso alteram significativamente o tecido social e, consequentemente, o cenário e o palco onde são engendradas as relações sociais. Tais alterações produzem novas necessidades na sociedade, pois, diante do quadro caótico do contexto de agudização da questão social, cada vez mais são imprescindíveis profissionais comprometidos com o enfrentamento das mais variadas expressões da questão social, profissionais que tenham, conforme sinaliza Iamamoto (1998, p. 80),

uma competência crítica capaz de decifrar a gênese dos processos sociais, suas desigualdades e as estratégias de ação para enfrentá-las. Supõe competência teórica e fidelidade ao movimento da realidade; competência técnica e ético-política que subordine o "como fazer" ou "o que fazer" e, este ao "dever ser", sem perder de vista seu enraizamento no processo social.

Tal competência sinalizada pela autora dificilmente será capaz de ser contemplada com o sujeito solitário, pois os desafios são imensos e sempre renováveis. Sendo assim, o próximo item irá abordar a ação do assistente social tensionada pela postura investigativa e pela busca interdisciplinar.

\section{0 exercício profissional do assistente social: uma equação tensionada pela postura investigativa e pela interdisciplinaridade}

O trabalho em conjunto tem sido uma tendência discutida como uma possibilidade em diversas áreas, não somente no Serviço Social. Atualmente os 
profissionais estão cada vez mais se conscientizando de que o trabalho solitário e isolado compromete as intervenções. No cotidiano de atuação profissional do AS não parece ser diferente; o que talvez precise mudar é o despertar generalizado dos profissionais no sentido de envidar esforços para que seja construída uma trajetória de trabalho conjunta, cada área oferecendo a sua contribuição e especificidade. Dada a importância da questão às intervenções na área de Serviço Social, abordar-se-á teoricamente a discussão sobre as relações entre as áreas do saber.

Inicialmente é preciso destacar que pensar interdisciplinaridade pode ensejar alguns equívocos — como a globalização de atividades —, no sentido de que pode ser realizada por apenas um profissional. Igualmente, e o mais preocupante, é a forma como se exterioriza a tão propalada interdisciplinaridade, sem que se afaste da hierarquização entre as áreas do saber, colocando-se umas como mais importantes que as outras, e o uso inconsequente do termo interdisciplinaridade, que o empobrece e banaliza.

A interdisciplinaridade precisa ser pensada como uma necessidade de interação e busca dos profissionais das diferentes áreas do conhecimento. No vernáculo pátrio, a palavra interdisciplinar (inter + disciplinar) refere-se ao que é comum a duas ou mais disciplinas ou ramos do conhecimento, enquanto multidisciplinar (de mui(i) + disciplina) abrange ou refere-se a muitas disciplinas (Ferreira, 1999).

$\mathrm{Na}$ maioria das vezes, as diferentes disciplinas estanques não contemplam as questões emergentes da sociedade; logo, não consideram a complexidade das múltiplas expressões da questão social. Refrações da questão social, como a violência, educação, segurança, preconceitos, a saúde do trabalhador e tantas outras, desafiam os profissionais diariamente, sendo-lhes demandadas questões que, por sua vez, não são passíveis de abordagens isoladas, havendo necessidade do diálogo com profissionais de diversas áreas.

Pode-se dizer que algumas das grandes limitações para se desenvolver um trabalho interdisciplinar são a falta de tempo, a sobrecarga de trabalho que demarca esse período em que se vive e a falta de oportunidades para planejamentos em equipe, surgindo, assim, a internet como alternativa para trabalhar conjuntamente, de maneira virtual. 
No Serviço Social, a interdisciplinaridade pode ser trabalhada como uma possibilidade já nos cursos de formação de graduação. Isso pode ser viabilizado na medida em que:

a) há uma profunda articulação do conhecimento advindo de uma formação que se pretende generalista, voltado para a busca da unidade;

b) o campo de atuação do Serviço Social é múltiplo e amplo, o que o torna particularmente complexo e promissor na interação, troca e parceria na intervenção profissional;

c) o projeto profissional da categoria prima por princípios profissionais que enaltecem a liberdade, a defesa dos direitos humanos, a luta pela ampliação e consolidação da cidadania, a defesa da democracia, o empenho na eliminação de todas as formas de preconceito, a garantia do pluralismo, o compromisso com a qualidade dos serviços prestados e com o aprimoramento intelectual. Tais princípios só se concretizam pela necessária articulação com outras categorias profissionais na luta pela equidade e justiça social que possibilitam o brilho coletivo.

De modo geral, para se exercitar a interdisciplinaridade proposta como possibilidade a ser investida já nos cursos de formação de graduação, é necessário ao Serviço Social o desenvolvimento de uma atitude interdisciplinar, conforme propõe Fazenda (2003), que a caracteriza por ser

uma atitude diante de alternativas para conhecer mais e melhor; atitude de espera ante os atos consumados, atitude de reciprocidade que impele à troca, que impele ao diálogo — ao diálogo com pares idênticos, com pares anônimos ou consigo mesmo - , atitude de humildade diante do próprio saber, atitude de perplexidade ante a possibilidade de desvendar novos saberes, atitude de desafio - desafio perante o novo, desafio de redimensionar o velho —, atitude de envolvimento e comprometimento com os projetos e com as pessoas neles envolvidas, atitude, pois, de compromisso em construir sempre da melhor forma possível, atitude de responsabilidade, mas sobretudo de alegria, de revelação, de encontro, enfim, de vida. (Fazenda, 2003, p. 82)

Sendo assim, a atitude interdisciplinar exige um exercício que precisa ser construído e conquistado aos poucos, a cada dia, nas ações cotidianas dos pro- 
fissionais de diferentes áreas, pois são diversas as atitudes propostas pela autora que precisam ser desenvolvidas: atitude de busca de alternativas, de espera, de reciprocidade, de humildade, de perplexidade, de desafio, de envolvimento e comprometimento, atitude de responsabilidade e também de alegria, de revelação, de encontro, enfim, de vida.

No âmbito do Serviço Social, encontra-se em Martinelli (1998b) um alerta para o fato de que, individualmente, não é possível transformar a realidade social, posto que não é como sujeito solitário que o assistente social vai se constituir nesse momento para atender a tantas demandas postas no cotidiano. Por isso é fundamental o sujeito coletivo e a superação da perspectiva do fazer profissional do sujeito solitário.

Nesse sentido, a mesma autora, em outro momento, chama a atenção para a divisão e fragmentação de saberes que muitas vezes permeiam a atuação dos diferentes profissionais e que levam à fragilização de suas intervenções: "Todos somos trabalhadores, lutamos por causas comuns e das diferenças de nossas profissões é que devem brotar as possibilidades" (Martinelli, 1998a, p. 150).

Tendo-se clareza de que os saberes são sempre marcados pela incompletude e insuficiência de intervenções, o diálogo entre as diferentes áreas pode ser um caminho para se consolidar as atitudes necessárias à interação, pois segundo Fazenda (2003, p. 69-70), "a metodologia interdisciplinar parte de uma liberdade científica, alicerça-se no diálogo e na colaboração, funda-se no desejo de inovar, criar, de ir além e exercita-se na arte de pesquisar [...] na qual se desenvolva a capacidade criativa de transformar a concreta realidade".

A interlocução entre as diferentes áreas do saber constitui-se como um movimento interno de transformação das ciências, precisa estar aberta para o diálogo, pois não emerge espontaneamente, mas exige uma luta árdua por mudança de posturas, construídas tanto no plano individual quanto no coletivo, daí a relevância da interdisciplinaridade.

\section{Considerações finais}

A atitude investigativa no cotidiano de trabalho do assistente social precisa ser concebida na medida em que possibilita uma ação profissional reflexiva 
nutrida pela intencionalidade e pelo planejamento. A ação planejada define um horizonte direcionado pelo desbravamento de ações permeadas de intencionalidade, portanto, plenas de sentido. Ações plenas de sentido ressoam como um tambor forte na pseudonaturalidade que encobre o véu das injustiças sociais refletidas nas penumbras da acomodação, naturalização e banalização.

Sendo assim, a ação do assistente social precisa ser norteada pela equação a seguir: postura investigativa + intervenção profissional + interdisciplinaridade = ação profissional com alcance social, que, por sua vez, será mediada pela intervenção nas diversas manifestações da questão social. Tal equação só adquirirá inteligibilidade e alcance social na medida em que for pautada pela interdisciplinaridade.

Além disso, é fundamental ao assistente social intencionalidade e clareza de finalidade, edificados com os princípios éticos construídos pela coletividade da categoria profissional no seu projeto ético-político e fortalecido pelas ações conjuntas com as diversas categorias profissionais e com os usuários em geral. A poesia de Fernando Pessoa, a seguir, desafia para um olhar profissional que vê sem preconceitos, de "saber ver sem estar a pensar", conforme o poeta:

O essencial é saber ver;

Saber ver sem estar a pensar,

Saber quando se vê

E nem pensar quando se vê

Nem ver quando se pensa.

Mas isso (tristes de nós que

trazemos a alma vestida!)

Isso exige um estudo profundo, uma aprendizagem de desaprender.

(Poema, Pessoa, 2006, p. 63)

Para que seja possível ao assistente social fortalecer seus espaços de atuação profissional na contemporaneidade é necessário um aprendizado da interdisciplinaridade, apreendida como uma possibilidade no exercício profissional, em que os esforços conjuntos sejam conjugados em prol da população usuária, onde seja possível despir a alma dos profissionais de preconceitos e despertá-los 
para "aprender a desaprender" para intervir de forma consistente, crítica, competente e, principalmente, propositiva e coletiva.

Finalmente, a atitude investigativa é o que fomenta uma ação do assistente social consistente, consequente e vice-versa. Enquanto a atitude investigativa é um movimento constante de busca, questionamentos, debruçamentos, planejamento para atuar na profissão, a ação profissional é consequência e, ao mesmo tempo, subsídio para essa investigação. Sendo assim, é preciso se desvencilhar dos limites do pragmatismo e incorporar a postura investigativa na ação do assistente social. Justamente daí que reside o mote do tensionamento da equação (postura investigativa + intervenção profissional + interdisciplinaridade $=$ ação profissional com alcance social) que está posto pela possibilidade da atitude interdisciplinar que só poderá ser incorporado plenamente com a postura investigativa.

Artigo recebido em abr./2009 - Aprovado em dez./2009

\section{Referências bibliográficas}

ASSOCIAÇÃO BRASILEIRA DE ENSINO E PESQUISA EM SERVIÇO SOCIAL - ABEPSS. Proposta básica para o projeto de formação profissional. O Serviço Social no século XXI. Serviço Social \& Sociedade, São Paulo, ano 17, n. 50, p. 143-171, abr. 1996.

ALMEIDA, N. L. T. Considerações para o exame do processo de trabalho do Serviço Social. Serviço Social \& Sociedade, São Paulo, ano 17, n. 52, p. 24-47, 1996.

BAPTISTA, Myrian Veras. A investigação em Serviço Social. CPIHTS — Centro Português de Investigação e História e Trabalho Social. São Paulo: Lisboa/Veras, 2001.

BARBOSA, R. N. C.; CARDOSO, F. G.; ALMEIDA, N. L. T. A categoria "processo de trabalho" e o trabalho do assistente social. Serviço Social \& Sociedade, São Paulo, ano 19, n. 58, p. 111-130, 1998.

BATTINI, Odária. Atitude investigativa e formação profissional: a falsa dicotomia. Serviço Social \& Sociedade, São Paulo, ano 15, n. 45, p. 142-146, ago. 1994. 
CARVALHO, M. C. Brant. O conhecimento da vida cotidiana: base necessária à prática social. In: NETTO, J. P.; CARVALHO, M. C. Brant. Cotidiano: conhecimento e crítica. 6. ed. São Paulo: Cortez, 2005. p. 13-63.

CONSELHO FEDERAL DE SERVIÇO SOCIAL - CFSS. Código de Ética Profissional. Resolução CFESS n. 273/93, de 13 de março de 1993. Institui o Código de Ética Profissional dos Assistentes Sociais e dá outras providências. Brasília, mar. 1993a.

Lei n. 8.662, de 7 de junho de 1993. Lei da Regulamentação da Profissão. Dispõe sobre a profissão de Assistente Social e dá outras providências. Brasília, 1993b.

DIRETRIZES gerais para o curso de Serviço Social (com base no currículo mínimo aprovado em Assembleia Geral Extraordinária de 8 novembro 1996). Formação Profissional: trajetórias e desafios. Cadernos ABESS, São Paulo, n. 7, p. 58-76, 1997.

FALEIROS, Vicente de Paula. Alternativas metodológicas da pesquisa em Serviço Social. Serviço Social \& Sociedade, São Paulo, ano 12, n. 21, p. 5-17, ago. 1986.

FAZENDA, Ivani C. A. Interdisciplinaridade: história, teoria e pesquisa. 11. ed. Campinas: Papirus, 2003.

FERREIRA, Aurélio Buarque de Holanda. Novo Aurélio século XXI: o dicionário da língua portuguesa. 3. ed. Rio de Janeiro: Nova Fronteira, 1999.

IAMAMOTO, Marilda Villela. O Serviço Social na contemporaneidade: trabalho e formação profissional. São Paulo: Cortez, 1998.

Projeto profissional, espaços ocupacionais e trabalho do assistente social na atualidade. In: CONSELHO FEDERAL DE SERVIÇO SOCIAL — CFESS. Atribuições privativas do(a) assistente social em questão. Brasília: CFESS, 2002. p. 13-50.

; CARVALHO, Raul de. Relações sociais e Serviço Social no Brasil: esboço de uma interpretação histórico-metodológica. 10. ed. São Paulo: Cortez, 1995.

KOSIK, Karel. Dialética do concreto. 6. reimpr. Trad. Célia Neves e Alderico Toríbio. Rio de Janeiro: Paz e Terra, 1995.

HOWARD, Ron. Uma mente brilhante (A beautiful mind). DVD vídeo (135 min). EUA, 2001.

MARTINELLI, M. L. Serviço Social: identidade e alienação. 5. ed. São Paulo: Cortez, 1997. 
MARTINELLI.M. L. Uma abordagem socioeducacional. In: MARTINELLI, Maria Lúcia; RODRIGUES, Maria Lucia; MUCHAIL, Salma Tannus (Orgs.). O uno e o múltiplo nas relações entre as áreas do saber. 2. ed. São Paulo: Cortez, 1998a. p. 139151.

O Serviço Social na transição para o próximo milênio: desafios e perspectivas. Serviço Social \& Sociedade, São Paulo, n. 57, p. 133-148, 1998 b.

(Org.). O uso das abordagens qualitativas na pesquisa em Serviço Social: um instigante desafio. São Paulo: Veras: 1994. (Caderno do Núcleo de Estudos e Pesquisa sobre Identidade — Nepi, n. 1).

MARX, Karl; ENGELS, Friedrich. A ideologia alemã. Trad. Luiz Cláudio de Castro e Costa. São Paulo: Martins Fontes, 2002.

MINAYO, Maria Cecília de Souza (Org.). Pesquisa social: teoria, método e criatividade. 11. ed. Petrópolis: Vozes, 1999.

MIOTO, Regina Célia Tamaso. Trabalho com famílias: um desafio para os assistentes sociais. Textos \& Contextos, n. 3, p. 1-14, dez. 2004. Disponível em: <http://revistaseletronicas.pucrs.br/>. Acesso em: $1^{\circ}$ ago. 2009.

NETTO, José P. A construção do projeto ético-político do Serviço Social frente à crise contemporânea. In: Capacitação em Serviço Social e Política Social: crise contemporânea, questão social e serviço social: módulo 1. Brasília, Cead/UnB/CFESS/Abepss, 1999. p. 91-110.

NOGUEIRA, Vera Maria Ribeiro. Intervenção profissional: legitimidade em debate. Katálysis, Florianópolis, v. 8, n. 2, p.185-192, jul./dez. 2005.

PESSOA, Fernando Antonio Nogueira. Poemas completos de Alberto Caeiro. Coleção a obra prima de cada autor. São Paulo: Martin Claret, 2006.

1999.

. Nevoeiro. In: CASSAL, Sueli Tomazini (Org.). Poesias. Porto Alegre: L\&PM,

PRATES, Jane Cruz. Possibilidades de mediação entre a teoria marxiana e o trabalho do assistente social. Tese (Doutorado). Programa de Pós-Graduação em Serviço Social da Pontifícia Universidade Católica do Rio Grande do Sul. Porto Alegre, 2003.

SANT'ANA, Raquel S. O desafio da implantação do projeto ético-político de serviço social. Serviço Social \& Sociedade, São Paulo, ano 21, n. 62, p. 68-72, 2000.

SETÚBAL, Aglair Alencar. Pesquisa em Serviço Social: utopia e realidade. 2. ed. São Paulo: Cortez, 2002. 
SILVA, José Fernando Siqueira da. Pesquisa e produção do conhecimento em Serviço Social. Textos \& Contextos, Porto Alegre, v. 6, n. 2, dez. 2007. Disponível em: <http:// revistaseletronicas.pucrs.br/ojs/index.php/fass/article/viewFile/2319/1810>. Acesso em: 5 ago. 2008.

SILVA, Maria Lúcia Lopes da. Um novo fazer profissional. In: Capacitação em Serviço Social e política social: módulo 04. Brasília: NED/Cead, Universidade de Brasília —UnB, 1999. p. 111-124. 